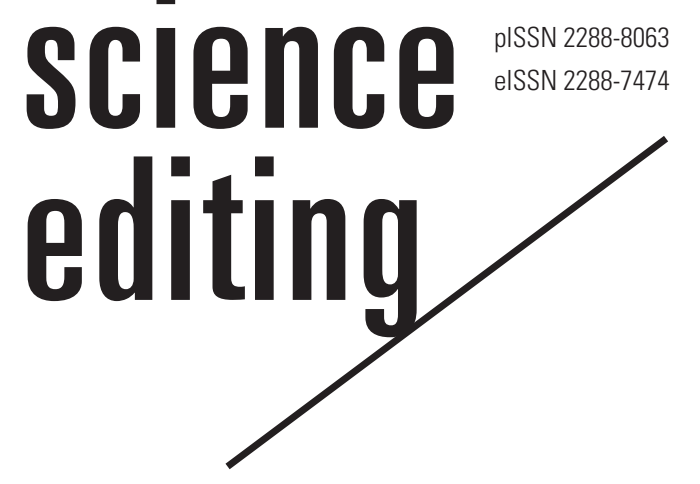

\title{
International academic publishing in Vietnam: policy efficiency and room for development
}

\author{
Thanh-Thao Phan Thi' ${ }^{1}$ Hiep-Hung Pham ${ }^{2,3}$, Huong-Linh Nguyen ${ }^{4}$, Linh-Chi Nguyen ${ }^{2}$ \\ ${ }^{1}$ The Reduvation Research Team, Thanh Do University, Hanoi, Vietnam; ${ }^{2}$ EdLab Asia Educational Research and Development \\ Centre, Hanoi, Vietnam; ${ }^{3}$ Center for Research and Practice on Education, Phu Xuan University, Hue City, Vietnam; ${ }^{4}$ Information \\ Technology, College of Business, Missouri State University, Springfield, MO, USA
}

\section{Introduction}

The purpose of this essay is two-fold. First, it evaluates the efficiency of two recent policies regarding international academic publishing in Vietnam: the new regulation on doctoral education and the establishment of the National Foundation for Science and Technology Development (NAFOSTED). Second, it outlines some possible avenues for further promotion of research in Vietnam.

\section{Vietnam's Policies regarding International Publishing}

If we had to choose the policy of the government that has had the most impact on promoting international publishing in Vietnam in recent years, we would not hesitate to "vote" for the regulation on doctoral training promulgated together with Circular No. 08/2017/QĐ-BGDĐT of the Ministry of Education and Training. Our opinion, therefore, may not align with the consensus of many others that the NAFOSTED was the most critical 'catalyst' for international publishing in Vietnam [1]. Let us view the role of NAFOSTED from a different angle. The establishment of NAFOSTED should be considered as the 'opening shot' to help Vietnamese scientists receive their first incentive from the government to publish internationally. In other words, the launching of NAFOSTED in 2008 helped encourage the Vietnamese scientific community to overcome their inertia and to publish for the first-time articles in international journals with $100 \%$ domestic authorship or with a team of authors led by domestic researchers (instead of depending or relying too much on international cooperation as before). However, the impact of Circular 08 is broader. To some extent, Circular 08 can be considered as a 'publish or perish' policy (for the first time in Vietnam). NAFOSTED only acts as one of multiple funding sources for research activity; scientists who do not want to publish internationally will still be able to find other funding sources. With Circular 08, we have for the first time a mandatory regulation whereby $\mathrm{PhD}$ students will not be allowed to graduate if they do not have interna- 
tional publications; similarly, university lecturers will not be able to take a supervisory role if they have not authored the required number of international publications. The 'publish or perish' nature of Circular 08 is stronger than that of NAFOST$\mathrm{ED}$ in this respect.

We also want to briefly discuss the 'publish or perish' culture. We completely agree with van Dalen and Henkens [2] that 'publish or perish' scientific policies have disadvantages such as encouraging quantity instead of quality. However, for countries that are still at an early stage of international integration in research, having 'publish or perish' policies like Circular 08 is critical. In our recent study [3], we divided the process of international integration of research in Vietnam into three phases: (1) 2008 and earlier: the period lacking policies to encourage international publishing; (2) 2008-2017: the beginning of international publishing in academia; and (3) 2017 to present: the period of formation and expansion.

Two crucial milestones mark these three phases: 2008 (the year NAFOSTED officially came into operation) and 2017 (the year Circular 08 was issued). Fig. 1 shows the number of international publications from Vietnam according to the three periods mentioned above, which we aggregated from the Clarivate Web of Science database [4]. This figure clearly illustrates the three phases associated with the two time points we listed above.

\section{Room for Development}

Strategies to attract talent to return

Although there are no specific data, we believe that Vietnam- ese researchers returning from abroad have made significant contributions to the breakthrough of Vietnam's international publications in recent years. In other words, the wave of Vietnamese students who went abroad in the 2000s has begun to produce fruitful achievements for the country. The scientists born in the 1970s and 1980s, who are now mature in terms of both health and expertise, have significantly contributed to Vietnam's achievements in international publications in recent years. Here are a few names with remarkable contributions: Prof. Pham Hoang Hiep (alumni of Sweden, Ta Quang Buu Prize, Ramanujan Prize, mathematics, born in the 1980s), Prof. Nguyen Van Hieu (alumni of the Netherlands, Ta Quang Buu Prize, physics, born in the 1970s), Prof. Phan Thanh Son Nam (alumni of the UK and USA, Ta Quang Buu Prize, Asian Scientist Award, chemistry, born in the 1970s), Dr. Nguyen Viet Cuong (alumni of the Netherlands, top 5\% of global economists, born in the 1970s).

In the coming years, we will need a well-planned strategy to properly support this cohort of scientists. The current coronavirus disease 2019 (COVID-19) pandemic has severely affected academic work in Western countries [5] and narrowed the opportunities for expatriate scientists [6], which might also be the case for Vietnamese scientists working abroad. Nevertheless, on average, compared to their counterparts residing in Vietnam, the research capacity of these academic expatriates is still more advanced. Amidst the wave of overseas Vietnamese returning home [7], this is an opportunity for domestic higher education institutions and research institutions to attract highly qualified and well-trained scholars from abroad.

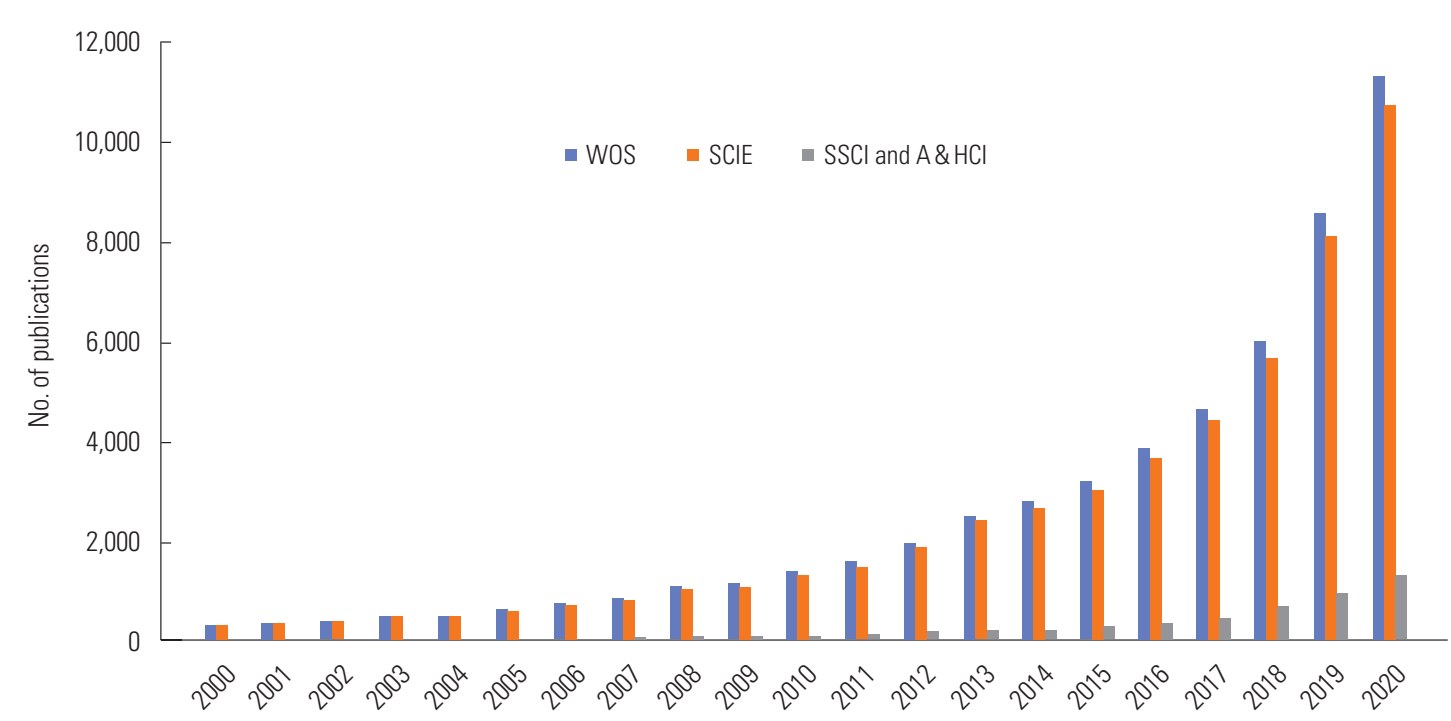

Fig. 1. International publications from Vietnam from 2000 to 2020. WOS, Web of Science; SCIE, Science Citation Index Expanded; SSCI, Social Sciences Citation Index; A\& HCl, Arts \& Humanities Citation Index. Data source: authors synthesized from Web of Science [4]. 


\section{The role of research groups}

For years, building strong research groups has been a strategy implemented by many higher education institutions throughout Vietnam. This strategy has helped raise domestic standards for both the quantity and quality of scientific research to meet international standards. A series of robust and potential research groups at higher education institutions throughout the country have been established over the years [8], such as the teams of Hanoi National University [9], Hanoi University of Science and Technology, Thuy Loi University [10], Phenikaa University [11], and Thanh Do University [12]. The effectiveness of the model of scientific team formation has been proven in many previous studies $[13,14]$. Our recent survey of educational researchers [15] also showed that the most important factor impacting researchers' international publishing practices was collaboration with domestic and international peers. In other words, establishing research groups, which foster collaborative relationships, is the most important factor for promoting international publishing_not funding or English proficiency, as most people assume.

Circular 08, on the one hand, resulted in a significant reduction in the number of enrollments at doctoral programs [16]; on the other hand, it has brought an opportunity for Vietnam universities and research institutions to innovate their doctoral programs to be higher-quality and more effective. Furthermore, it is time to recognize the importance of having quality domestic doctoral programs for providing high-quality human resources, instead of relying solely on training abroad like before. Efforts made by other countries within the region, such as Korea, China, Singapore, Thailand, and Taiwan, in innovating doctoral programs to meet international standards will undoubtedly give us valuable lessons.

According to our own observations, the above countries have these common directions in their strategies for the renovation of doctoral programs: the goal is to reach international quality accreditation standards; the method is to conduct teaching in English and attract international $\mathrm{PhD}$ students, grant scholarships to $\mathrm{PhD}$ students, and integrate $\mathrm{PhD}$ students with research groups in the university; the requirements are that $\mathrm{PhD}$ students work full-time and often have to have additional teaching experience, as well as international publications in Clarivate/Scopus journals as a prerequisite for graduation.

\section{Interdisciplinary, multidisciplinary, and transdisciplinary} research

In the international academic world, interdisciplinary, multidisciplinary, and transdisciplinary research has now become an inexorable trend [17]. Those who do not catch up will most likely be left behind. This is inevitable and understandable for the following reasons. First, complex single-disciplin- ary problems have either been entirely solved by earlier scientists or cannot be solved by single-disciplinary approaches. Second, the topical issues of life are themselves interdisciplinary, multidisciplinary, and transdisciplinary; therefore, it is difficult to deal with those issues through a single-disciplinary approach. For historical reasons, higher education institutions in Vietnam, except for a few exceptional cases such as two Vietnam National Universities, are mainly single-disciplinary schools, which is a significant hindrance.

In recent years, we have started to see signs of many universities aiming to develop the multidisciplinary university model [18], which can be seen as a good sign. Some other strategies to promote interdisciplinary, multidisciplinary, and transdisciplinary research are as follows: (1) prioritize funding for interdisciplinary, multidisciplinary, and transdisciplinary research; (2) prioritize research groups whose members have diverse academic backgrounds; (3) simplify the requirements when learners want to change majors/specializations (from undergraduate to master's programs, from master's to doctoral programs); and (4) open graduate training programs with interdisciplinary, multidisciplinary, and transdisciplinary orientations.

\section{Conclusion}

In recent years, Vietnam has made considerable progress in the field of international publishing, with Circular 08 playing, in our view, the most important role. The "publish or perish" nature of Circular 08 has forced Vietnamese scientists to accelerate their productivity, resulting in an increasing number of international publications. In the future, there should be more strategies to support scholars who are expatriate returnees and domestic research groups, who have contributed significantly to increasing the country's international publication output. We also recommend that the government should focus on innovation in doctoral programs and the promotion of interdisciplinary, multidisciplinary, and transdisciplinary research.

\section{Conflict of Interest}

No potential conflict of interest relevant to this article was reported.

\section{Funding}

The authors received no financial support for this article. 


\section{References}

1. Khoi N. The "catalyst" in scientific research. Today [Internet]. 2020 Jul 21 [cited 2021 May 16]. Available from: https://nhandan.vn/baothoinay-xahoi-vande/chat-xuctac-trong-nghien-cuu-khoa-hoc-609487/

2. van Dalen HP, Henkens K. Intended and unintended consequences of a publish-or-perish culture: a worldwide survey. J Am Soc Inf Sci Technol 2012;63:1282-93. https://doi. org/10.1002/asi.22636

3. Nguyen TT, Pham HH, Vuong QH, Cao QT, Dinh VH, Nguyen DD. The adoption of international publishing within Vietnamese academia from 1986 to 2020: a review. Learn Publ 2021;34:175-86. https://doi.org/10.1002/leap. 1340

4. Clarivate Analytics. Web of Science: the world's largest publisher-neutral citation index and research intelligence platform [Internet]. London: Clarivate Analytics; c2021 [cited 2021 May 16]. Available from: https://www.webofknowledge. com

5. Langin K. US faculty job market tanks. Science 2020;370: 272-3. https://doi.org/10.1126/science.370.6514.272

6. Arnold C, Woolston C. Uncertainty plagues junior researchers from underprivileged backgrounds amid pandemic. Nature 2020;588:355-7. https://doi.org/10.1038/ d41586-020-03465-0

7. Anh P. 75,000 Vietnamese repatriated amid coronavirus pandemic. VNExpress International [Internet]. 2020 Dec 28 [cited 2021 May 16]. Available from: https://e.vnexpress.net/news/news/75-000-vietnamese-repatriatedamid-coronavirus-pandemic-4213029.html

8. Xuan M, Son G. Developing research groups in the university. Nhan Dan [Internet]. 2019 May 14 [cited 2021 May 16]. Available from: https://nhandan.com.vn/dien-danGiao-duc/phat-trien-cac-nhom-nghien-cuu-trong-truongdai-hoc-358544

9. Luong T. Developing research groups in universities: the inevitable trend. VOV [Internet]. 2014 May 8 [cited 2021 May 16]. Available from: https://vov.vn/xa-hoi/phat-trien-nhomnghien-cuu-trong-truong-dh-xu-the-tat-yeu-325151.vov

10. Phong T. Launching 4 strong research groups. Tien Phong
[Internet]. 2020 July 23 [cited 2021 May 16]. Available from: https://tienphong.vn/ra-mat-4-nhom-nghien-cuumanh-post1258857.tpo

11. Ngoc B. Phenikaa University launches strong research groups. VnExpress [Internet]. 2019 May 15 [cited 2021 May 1]. Available from: https://vnexpress.net/truong-dai-hocphenikaa-ra-mat-cac-nhom-nghien-cuu-manh-3923390. html

12. Thanh Do University. Reduvation: research group on educational sciences. Model of cooperation between universities and non-public research institutes [Internet]. Hanoi: Thanh Do University; 2020 [cited 2021 May 16]. Available from: https://www.thanhdo.edu.vn/reduvation-nhom-nghien-cuu-ve-khoa-hoc-giao-duc-mo-hinh-phoi-hop-giua-dai-hoc-va-vien-nghien-cuu-ngoai-cong-lap

13. Bordons M, Zulueta MA. Comparison of research team activity in two biomedical fields. Scientometrics 1997;40: 423-36. https://doi.org/10.1007/BF02459290

14. Milojevic S. Principles of scientific research team formation and evolution. Proc Natl Acad Sci U S A 2014;111:3984-9. https://doi.org/10.1073/pnas.1309723111

15. Trinh TP, Tran T, Le HT, Nguyen TT, Pham HH. Factors impacting international-indexed publishing among Vietnamese educational researchers. Learn Publ 2020;33:41929. https://doi.org/10.1002/leap.1323

16. Education and Times. Difficulties in enrollment and doctoral training: looking directly at reality for real training. Education and Times [Internet]. 2020 Jun 4 [cited 2021 May 16]. Available from: https://giaoducthoidai.vn/thoisu/kho-khan-trong-tuyen-sinh-dao-tao-tien-si-nhinthang-thuc-te-de-dao-tao-that-20200604090642690.html

17. Guimaraes $\mathrm{MH}$, Pohl C, Bina O, Varanda $\mathrm{M}$. Who is doing inter- and transdisciplinary research, and why? An empirical study of motivations, attitudes, skills, and behaviours. Futures 2019;112:102441. https://doi.org/10.1016/j.futures. 2019.102441

18. Huong T. Multidisciplinary university: the destination must be quality. Great Unity [Internet]. 2021 Jan 28 [cited 2021 May 16]. Available from: http://daidoanket.vn/daihoc-da-nganh-dich-den-phai-la-chat-luong-551351.html 